\section{Julia Gurganus: Russia: Playing a Geopolitical Game in Latin America, Washington, D.C.: Carnegie Endowment for International Peace, 2018.}

\author{
Besprochen von Remko Leemhuis, AJC Berlin Ramer Institute, \\ Consultant on Antisemitism Affairs, Berlin; \\ E-mail: LeemhuisR@ajc.org \\ https://doi.org/10.1515/sirius-2018-4014
}

Seit Vladimir Putin im Jahr 2012 offiziell in das Präsidentenamt zurückgekehrt ist, verfolgt das Regime im Kreml aggressiver denn je das Ziel seinen geopolitischen Einfluss auszubauen. Unverkennbar sind die Ambitionen nicht regional beschränkt. Moskau versucht auch in weiter entfernten Regionen wie etwa Südamerika Fuß zu fassen um wieder in den Rang einer Supermacht aufzusteigen oder zumindest dieses Bild zu produzieren. Julia Gurganus, Russlandexpertin der CIA, untersucht in ihrer vorliegenden Studie die wesentlichen Aspekte und möglichen Folgen dieser Bemühungen vor dem Hintergrund der politischen Umbrüche in einer ganzen Anzahl von Ländern des Kontinents im Jahr 2018.

Nur auf den ersten Blick ist das verstärkte Engagement Russlands in Südamerika überraschend, denn bereits die Sowjetunion pflegte gute Beziehungen zu einigen Staaten der Region, wobei Kuba nur das offenkundigste Beispiel ist. Aufgrund dieser historisch gewachsenen Beziehungen kann Moskau auf gut etablierte Netzwerke zurückgreifen. Die Ziele des Engagements in Südamerika sind, so Gurganus, damals wie heute die gleichen: eine Präsenz in der Nachbarschaft der USA zu etablieren und langfristig regional als auch global die Führungsrolle der USA zu unterminieren und die liberale Weltordnung zugunsten eines multipolaren Systems zu zerstören. Indes sind die russischen Aktivitäten in Südamerika nicht alleine Ausdruck außenpolitischer Erwägungen. Diese Einflussnahme in Lateinamerika, wie auch in anderen Regionen, hat für den Kreml auch eine wichtige innenpolitische Dimension.
Da Putin kaum über demokratische Legitimation in Russland verfügt, nutzt er die Außenpolitik auch um sich als starker Führer in Szene zu setzen, der sein Land wieder auf Augenhöhe mit den USA und China geführt hat. Dieses Bild von Russland im internationalen System ist somit ein wesentliches Element seiner Herrschaftslegitimation.

Obwohl Moskau, wie bereits zu Zeiten des Kalten Krieges, nur über limitierte Ressourcen verfügt und nicht im größerem Maßstab militärisch und ökonomisch in Südamerika Fuß fassen kann, so darf nicht übersehen werden, dass das Regime bewiesen hat, dass es mit überschaubaren Mitteln im politischen Geschehen souveräner Staaten erheblichen Einfluss nehmen kann. Ein Blick auf die Handelsbilanz verdeutlicht, dass Moskau den Vereinigten Staaten nur wenig entgegenzusetzen hat, betrug der gesamte Handel zwischen dem Land und den südamerikanischen Staaten 2016 doch lediglich 12 Milliarden US-Dollar. Im Zentrum des Handels steht der Verkauf von Waffen, wobei Russland mit 20 Prozent den gleichen Marktanteil hält wie die Vereinigten Staaten. Indes kommt Russland entgegen, dass einige Länder bereits mit sowjetischem Gerät vertraut sind und die zumeist staatlichen russischen Rüstungskonzerne ihr Material aus politischen Erwägungen zu deutlich günstigeren Konditionen als die Konkurrenz anbieten können. Zweifellos ist es ebenso ein Wettbewerbsvorteil, dass sich das Regime von Putin um Fragen der Menschen- und Bürgerrechte, im Gegensatz zu westlichen Demokratien nicht kümmern muss. Auch bei der Vergabe von Krediten und Wirtschaftshilfe kann Moskau deutlich flexibler agieren als etwa die Weltbank. Die Wirtschafts- und Handelsbeziehungen sind für Moskau, so hebt Gurganus hervor, nicht zuletzt auch deswegen relevant, da Moskau versucht die Verluste durch die westlichen Sanktionen, die nach der Annexion der Krim und der Invasion in der Ostukraine verhängt wurden, auszugleichen.

Doch nicht nur ökonomisch versucht Moskau immer stärker Fuß zu fassen. Julia Gurganus weist darauf hin, dass russische Staatsmedien wie ,Russia Today (RT) und ,Sputnik' seit dem Jahr 2009 und dem Jahr 2014 über spanischsprachige Programme verfügen. Verbunden mit Online-Inhalten sind diese Angebote, wie in Europa und anderen Regionen der Welt, Teil des Informationskrieges des Kremls. Die Autorin hebt in diesem Zusammenhang hervor, dass wenn es dem Putin Regime gelänge, die öffentliche Stimmung in nur einem oder zwei Schlüsselländern gegen die USA zu kippen, Washington dies vor enorme Probleme stellen könnte.

Erkennbar wird aus der Studie indes aber auch, dass Russland nur dann in der Lage ist seinen Einfluss zu vergrößern, wenn Washington sich zurückzieht oder die Partnerschaften in der Region vernachlässigt. Gerade mit 
Blick auf Mexiko wird deutlich, dass die Rhetorik und Politik des derzeitigen US-Präsidenten Resonanzräume für Politiker wie den neugewählten Präsidenten Andrés Manuel López Obrador schafft oder erweitert, die den USA weniger freundschaftlich verbunden sind. Der Linkspopulist hat schließlich in seinem Wahlkampf die Attacken aus Washington genutzt um seinerseits Donald Trump anzugreifen und die Spannungen zwischen beiden Ländern zu verschärfen. Sollte dieser bisher nur verbale Schlagabtausch zu ökonomischen Turbulenzen oder gar einem Ende des Freihandelsabkommens NAFTA führen, so dürfte Russland sich zweifellos als Handelspartner anbieten (der allerdings wenig zu bieten hat), oder vielleicht versuchen an der Südgrenze der Vereinigten Staaten eine militärische Präsenz zu etablieren.

Deutlich wird an der Politik des Kremls in Südamerika, was auch in anderen Teilen der Welt gilt: Das Land agiert weit über seinen realen Möglichkeiten und kann nur dort Einfluss gewinnen, wo die liberalen Demokratien sich zurückziehen und ihre Ordnungspolitik und Funktion aufgeben. Robustes ökonomisches und politisches Engagement seitens des Westens, verbunden mit Anreizen demokratische Strukturen zu stabilisieren, und auszubauen sind nach wie vor die beste Garantie gegen das Gift der illiberalen Propaganda des Putin-Regimes. Dafür bedarf es aber, wie in jeder Herausforderung durch Moskau, den politischen Willen, die Auseinandersetzung anzunehmen und die Probleme deutlich benennen. Konzessionslose Zugeständnisse an Moskau, so haben die letzten Jahre zweifellos gezeigt, werden von Putin als Schwäche und als Ermunterung verstanden, seine Offensive gegen den Westen fortzusetzen.

https://carnegieendowment.org/2018/05/03/russiaplaying-geopolitical-game-in-latin-america-pub-76228 